THE current study was undertaken to evaluate the effects of granulocyte-macrophage colony-stimulating factor (GM-CSF) and cyclic AMP (cAMP) signaling in teraction on human neutrophil apoptosis, either occurring spontaneously or induced by Fas antigen activation. Results show that GM-CSF, dibutyryl cAMP (a cAMP analog) and forskolin (an adenylate cyclase activator) are all able to suppress spontaneous neutrophil cell death. Of note however, when GM-CSF is used in combination with cAMP-elevating agents, an additive effect on neutrophil survival is observed with dibutyryl cAMP only, whereas supplementation of cell cultures with GM-CSF and forskolin results in a progressive reduction of an tiapoptotic effects exerted by the single compounds. Moreover, although dibutyryl cAMP and forskolin do not affect Fas-triggered apoptotic events, they are still able to modulate the GM-CSF capacity to prolong neutrophil survival following an ti-Fas IgM cell challenge, with effects similar to those respectively exerted on spontaneous neutrophil apoptosis. The data indicate that GM-CSF $m$ ay negatively modulate the cAMP-mediated an tiapoptotic pathway in human neutrophils, likely via the inhibition of adenylate cyclase activity. This would prevent an abnormal neutrophil survival as a result of cAMP signaling stimulation, which provides a novel in sight in to the role of GM-CSF as a physiological regulator of myeloid cell turnover.

Key words: Polymorphonuclear cells, Apoptosis, Fas, GMCSF, Dibutyryl cAMP, Forskolin

\section{Effects of granulocyte-macrophage colony-stimulating factor and cyclic AMP interaction on human neutrophil apoptosis}

\author{
Cosimo Tortorella, ${ }^{\text {CA }}$ Giuseppina Piazzolla, \\ Felice Spaccavento and Salvatore Antonaci
}

Department of Internal Medicine, Immunology and Infectious Diseases, University of Bari Medical School, Bari 70124, Italy

\footnotetext{
${ }^{\mathrm{CA}}$ Corresponding Author

Tel: $(+39) 805478787$

Fax: (+39) 805478670
}

\section{Introduction}

Polymorphonuclear leukocytes (PMN) play a critical role in host defense against invading microorganisms, ${ }^{1}$ as well as in local and systemic inflammatory diseases. ${ }^{2}$ The maintenance of circulating PMN levels within physiologic limits is thus crucial for the host. Since mature neutrophils are terminally differentiated cells incapable of self-renew $\mathrm{al}^{3}{ }^{3}$ such an event is made possible by a continuous highly controlled balance between the entry of newborn cells into the blood and the elimination of senescent PMN in the tissues. In the last few years, large evidence has been provided that programmed cell death or apoptosis is the major mechanism for limiting PMN amount in vivo. ${ }^{4-7}$ Different from necrosis, apoptosis is characterized by specific morphologic and biochemical events including cell shrinkage, cytoplasmic vacuolation, membrane blebbing (zeiosis), chromatin condensation and nuclear fragmentation associated with endonucleolytic DNA cleavage. ${ }^{8}$ Apoptotic PMN are then recognized and engulfed by macrophages via the vitronectin receptor, ${ }^{9}$ thus preventing the possible occurrence of tissue damage as a consequence of toxic product leakage from destroyed cells.
Although neutrophils appear to be committed to apoptotic cell death in vivo as well as in vitro, this process is susceptible to modulation by different compounds. In this context, it has been reported that Fas antigen engagement on the PMN surface, either by Fas ligand binding or binding of agonistic anti-Fas IgM antibody, markedly accelerates ne utrophil apoptosis. $^{10,11}$ On the contrary, many PMN activators, including proinflammatory cytokines and bacterial products are all able to prolong the life span and the functional activity of PMN in vitro..$^{4,10-14}$ In this regard, cyclic AMP (cAMP) has been shown to modulate the apoptotic process, exhibiting a cell-type dependent effect. Thus, whereas cAMP-elevating agents accelerate apoptosis in a variety of cell types, including thymocytes and $\mathrm{B}$ lymphocytes, ${ }^{15,16}$ they suppress neutrophil cell death occurring spontaneously in vitro. ${ }^{17,18}$

In spite of these findings, the mechanisms by which the different molecules influence neutrophil survival are largely unknown. In this study, we have investigated the effects of granulocyte-macrophage colony-stimulating factor (GM-CSF)- and cAMP-mediated pathway interaction on apoptotic outcome of human neutrophils. To this aim, dibutyryl cAMP (a 
cAMP analog) or forskolin (an adenylate cyclase activator), used alone or in combination with GM-CSF, have been supplemented to PMN cell cultures, and the occurrence of apoptosis, either spontaneous or induced by Fas antigen activation, has been evaluated on the basis of typical morphological changes as well as quantitative assay of DNA fragmentation.

\section{Materials and Methods}

\section{Cell purification}

Human neutrophils were isolated from the peripheral blood of 25 healthy asymptomatic donors by a two stage procedure. First, venous blood, diluted $1: 4 \mathrm{w}$ ith phosphate buffered saline (0.02 M PBS; pH 7.2), was fractionated by Ficoll gradient centrifugation (Seromed-Biochem KG, Berlin, Germany) at $170 \mathrm{~g}$ for 45 min. ${ }^{19}$ Thereafter, the cell pellets were washed twice with PBS and mixed with a 6\% dextran $(40,000 \mathrm{mw})$ solution. Following sedimentation for $1 \mathrm{~h}$ at $37^{\circ} \mathrm{C}$, the PMN-rich supernatants were collected and centrifuged at $400 \mathrm{~g}$ for $10 \mathrm{~min}$. Pellets were then subjected to hypotonic lysis of erythrocytes and finally resuspended in RPMI-1640 (Sigma Chemical Co, Milan, Italy) supplemented with penicillin $(100 \mathrm{IU} / \mathrm{ml})$, streptomycin $(100 \mu \mathrm{g} / \mathrm{ml})$, L-glutamine $(2 \mathrm{mM})$ and $10 \%$ heat-inactivated foetal calf serum (FCS) (complete medium). The preparation contained more than $95 \%$ PMN, of which more than $90 \%$ were ne utrophils, as determined by May Grünwald-Giemsa staining of cytocentrifuged samples.

All reagents were LPS-free, as assessed by the Limulus amoebocyte lysate assay (Sigma).

\section{Culture conditions}

PMN $\left(10^{6}\right.$ cells $/$ well in a total volume of $300 \mu \mathrm{l} /$ well $)$ were cultured at $37^{\circ} \mathrm{C}$ in humidified air containing $5 \%$ $\mathrm{CO}_{2}$ in 24-well cell culture clusters (Costar, Milan, Italy), in the absence or presence of GM-CSF (1000 UI/ml), dibutyryl cAMP $\left(2 \times 10^{-6} \mathrm{M}\right.$ up to $2 \times 10^{-3} \mathrm{M}$ ), forskolin $\left(10^{-6} \mathrm{M}\right.$ up to $10^{-4} \mathrm{M}$ ) (all purchased from Sigma), or a combination of GM-CSF and either of cAMP-elevating agents. After $24 \mathrm{~h}$ incubation, cells were removed, washed once in RPMI-1640 and used for the different apoptotic assays. In another series of ex periments, the effects of cAMP elevating agents on GM-CSF capacity to inhibit neutrophil apoptosis induced by Fas was evaluated. PMN cell cultures were thus pretreated for $2 \mathrm{~h}$ with GM-CSF or dibutyryl cAMP and forskolin, both used alone or in combination with GM-CSF, and then supplemented with murine monoclonal antibody $(\mathrm{mAb}) \mathrm{CH}-11$ (anti-human Fas IgM inducing apoptosis; $150 \mathrm{ng} / \mathrm{ml}$ ) for a further $12 \mathrm{~h}$ of incubation, before being processed for apoptotic analysis as described below.

\section{Analysis of apoptotic cellular morphology of PMN}

For the analysis of apoptotic morphology, cytospin preparations of PMN were stained with May Grünwald-Giemsa and examined by oil-immersion light microscopy at $600 \times$ final magnification. Five hundred cells were counted per sample and data are reported as percentage of cells with apoptotic morphology, as assessed according to the following criteria: nuclear condensation eventually resulting in apoptotic bodies, decrease in cell size and cytoplasmic vacuolation. ${ }^{8}$

\section{Quantitation of DNA fragmentation}

Quantitation of DNA fragmentation was performed by determination of fractional solubilized DNA by diphenylamine assay, as described elsewhere. ${ }^{20}$ In brief, $3 \times 10^{6}$ PMN were centrifuged for $10 \mathrm{~min}$ at $200 \mathrm{~g}$ and the resulting cell pellets lysed by addition of $0.5 \mathrm{ml}$ TTE solution (10 mM Tris $\mathrm{HCl} \mathrm{pH} 7.4 ; 1 \mathrm{mM}$ EDTA; $0.2 \%$ Triton X-100). Thereafter, lysates were centrifuged for $10 \mathrm{~min}$ at $13,000 \mathrm{~g}$ to separate intact chromatin (pellet) from soluble low molecular weight DNA (supernatant). Supernatants were then carefully transferred to new tubes whereas pellets were supplemented with $0.5 \mathrm{ml}$ TTE solution. After overnight precipitation with $0.5 \mathrm{ml}$ of $25 \%$ TCA (trichloroace tic acid), DNA was centrifuged for $10 \mathrm{~min}$ at $13,000 \mathrm{~g}$, supernatants were aspirated and discarded, and pellets were added with $80 \mu \mathrm{l}$ of 5\% TCA before being placed in a heating block for $15 \mathrm{~min}$ at $90^{\circ} \mathrm{C}$ to hydrolyze DNA. Each tube was then supplemented with $160 \mu \mathrm{l}$ of freshly prepared diphenylamine (DPA) reagent [150 mg DPA (Sigma) in a polypropylene tube; $10 \mathrm{ml}$ glacial acetic acid; $150 \mu \mathrm{l}$ concentrated sulfuric acid; $50 \mu \mathrm{l}$ acetaldehyde $(16 \mathrm{mg} / \mathrm{ml})]$ and colour was allowed to develop for $4 \mathrm{~h}$ at $37^{\circ} \mathrm{C}$. Two hundred $\mu \mathrm{l}$ of coloured solution was finally transferred to wells of a 96-w ell flat-bottomed ELISA plate and the optical density (OD) was determined in a multiwell scanning spectrophotometer (Titertek Multiscan MCC; Flow Laboratories, Milan, Italy), at a wavelength of $620 \mathrm{~nm}$. Data are reported as the percentage of soluble, low molecular weight DNA in comparison to total DNA.

\section{Statistical analysis}

Statistical analysis was performed by means of a paired $t$-test. $P$ values $<0.05$ were taken as statistically significant.

\section{Results}

In agreement with previous reports, ${ }^{4,10-13,17,18}$ here we find that both GM-CSF and cAMP-elevating agents 
Table 1. Modulating effects of GM-CSF and CAMP-elevating agents on spontaneous neutrophil apoptosis ${ }^{a}$

\section{\% Apoptotic PMN}

Morphology DNA fragmentation

\begin{tabular}{lll} 
Nil & $62.4 \pm 7.2$ & $51.1 \pm 6.5$ \\
GM-CSF & $37.1 \pm 3.4^{*}$ & $31.8 \pm 2.6^{*}$ \\
Dibutyryl cAMP & & \\
$2 \times 10^{-6} \mathrm{M}$ & $50.4 \pm 5.1^{*}$ & $43.6 \pm 4.8^{*}$ \\
$2 \times 10^{-5} \mathrm{M}$ & $40.8 \pm 4.6^{*}$ & $36.7 \pm 3.2^{*}$ \\
$2 \times 10^{-3} \mathrm{M}$ & $11.9 \pm 1.9^{*}$ & $12.6 \pm 1.7^{*}$ \\
Forskolin & & \\
$10^{-6} \mathrm{M}$ & $60.2 \pm 6.8$ & $50.2 \pm 5.8$ \\
$10^{-5} \mathrm{M}$ & $57.9 \pm 4.9$ & $48.6 \pm 6.2$ \\
$10^{-4} \mathrm{M}$ & $39.6 \pm 3.4^{*}$ & $34.2 \pm 3.6^{*}$ \\
\hline
\end{tabular}

${ }^{a}$ Neutrophils were cultured in vitro in the absence or presence of GMCSF $(1000 \mathrm{Ul} / \mathrm{ml})$, dibutyryl cAMP or forskolin. After $24 \mathrm{~h}$ of incubation, aliquots of PMN were recovered and further processed for the assessment of apoptotic morphology, or the analysis of DNA fragmentation. Data represent the mean $\pm S D$ of percentage of cells showing features of apoptosis, or ratio of low to high molecular weight DNA expressed as a percentage, in 25 independent donors. Significance versus homologous cells cultured in medium alone: ${ }^{*} p<0.001$.

are able to prolong PMN survival (Table 1). With particular reference to the latter compounds, a dosedependent inhibition of neutrophil cell death is observed following supplementation of PMN cell cultures with dibutyryl cAMP, whereas the addition of forskolin significantly delays neutrophil apoptosis only at the highest concentrations used (see Table $1)$.

To gain insight into the mechanis ms by which these molecules influence apoptosis, the effects of cAMPand GM-CSF-dependent pathway interaction on neu- trophil cell death, either occurring spontaneously or induced by Fas antigen activation, have been assessed by means of DNA fragmentation analysis. As depicted in Fig. 1A, suboptimal concentrations of dibutyryl cAMP significantly enhances GM-CSF capacity to suppress spontaneous neutrophil apoptosis, whereas higher concentrations prolong PMN survival as effectively as the cyclic nucleotide alone. Interestingly, treatment of PMN cell cultures with forskolin and GMCSF gives rise to an opposite apoptotic outcome, with the cytokine suppressing the antiapoptotic activity exerted by forskolin, and increasing levels of forskolin determining a progressive reversal of cell survival advantage provided by GM-CSF (Fig. 1B).

As far as the effects on Fas-triggered neutrophil apoptosis is concerned, Fig. 2 illustrates that unlike GM-CSF, which determines a significant inhibition of apoptotic events, neither dibutyryl cAMP nor forskolin, even used at the highest concentrations, are able to reduce the appearance of DNA cleavage products, after PMN incubation for $12 \mathrm{~h}$. Of note however is that both cAMP-elevating agents prove to be effective in modulating the antiapoptotic activity of GM-CSF, with dibutyryl cAMP enhancing and forskolin inhibiting the cytokine capacity to prolong PMN survival following anti-Fas IgMmAb cell challenge (Fig. 3).

\section{Discussion}

Neutrophils have the shortest life span among leukocytes. Similarly, they rapidly die when maintained in vitro, exhibiting the morphological features of cells undergoing apoptosis. ${ }^{4-7}$ Our data confirm the capac-
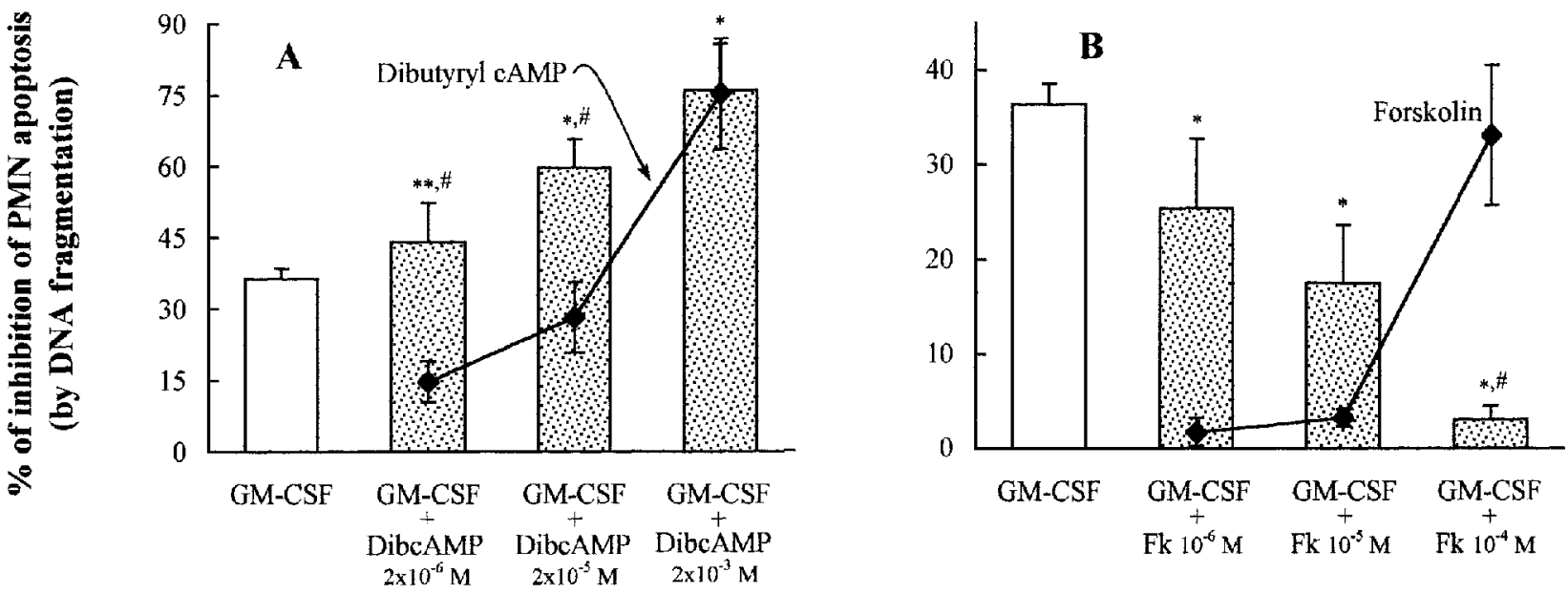

FIG. 1. Effects of GM-CSF and cAMP-elevating agent interaction on spontaneous neutrophil apoptosis. Neutrophils were cultured in vitro for $24 \mathrm{~h}$ in the absence or presence of GM-CSF (1000 Ul/ml; white columns), dibutyryl cAMP (panel A) and forskolin (panel B) (both represented with a solid line), or a combination of GM-CSF and either of cAMP-elevating agents (dotted columns). Cells were then recovered and further processed for the analysis of DNA fragmentation. Results are expressed as percentage of inhibition (mean \pm SD) of low to high molecular weight DNA ratio in treated compared to untreated cell cultures, and are obtained from 12 independent donors. Significance versus cell suspensions treated with GM-CSF only: ${ }^{* *} p<0.01$ and ${ }^{*} p<0.001$; significance versus PMN treated with homologous concentrations of dibutyryl cAMP or forskolin: $\# p<0.001$. 


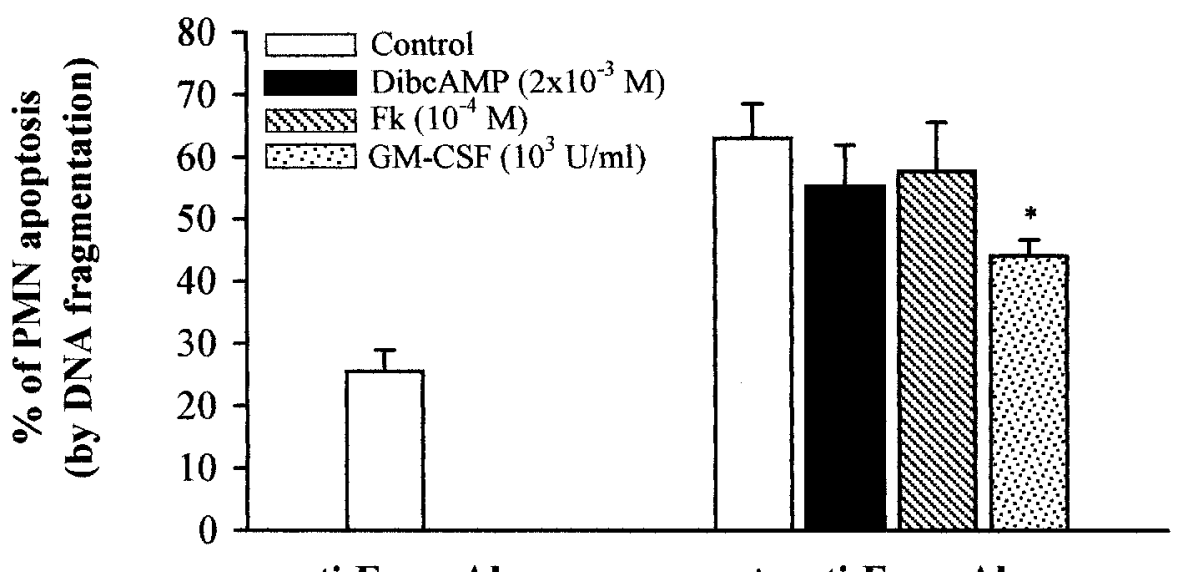

- anti-Fas mAb

+ anti-Fas mAb

FIG. 2. Differential effects of GM-CSF and cAMP-elevating agents on Fas-induced neutrophil apoptosis. PMN were pretreated with or without GM-CSF $(1000 \mathrm{Ul} / \mathrm{ml})$, dibutyryl cAMP $\left(2 \times 10^{-3} \mathrm{M}\right)$ or forskolin $\left(10^{-4} \mathrm{M}\right)$ for $2 \mathrm{~h}$, and then suppl emented with $\mathrm{mAb}$ $\mathrm{CH}-11(150 \mathrm{ng} / \mathrm{ml})$ or medium alone for a further $12 \mathrm{~h}$ of incubation, before DNA extraction and analysis. Results represent the ratio of DNA cleavage products to high molecular weight DNA expressed as percentage (mean \pm SD), in 15 healthy volunteers. Significance versus control: ${ }^{*} p<0.001$.

ity of GM-CSF ${ }^{4,10-13}$ and cAMP-elevating age nts ${ }^{17,18}$ to delay this process. Nevertheless, the GM-CSF inhibition of forskolin-mediated antiapoptotic activity outlines the possibility that the cytokine acts as a physiological regulator of cAMP-signaling in human neutrophils. The additive effects between dibutyryl cAMP, which bypasses the adenylate cyclase, and GMCSF indicate that such an inhibitory function may involve the adenylate cyclase, a key enzyme in the cAMP-mediated pathway, further suggesting that a

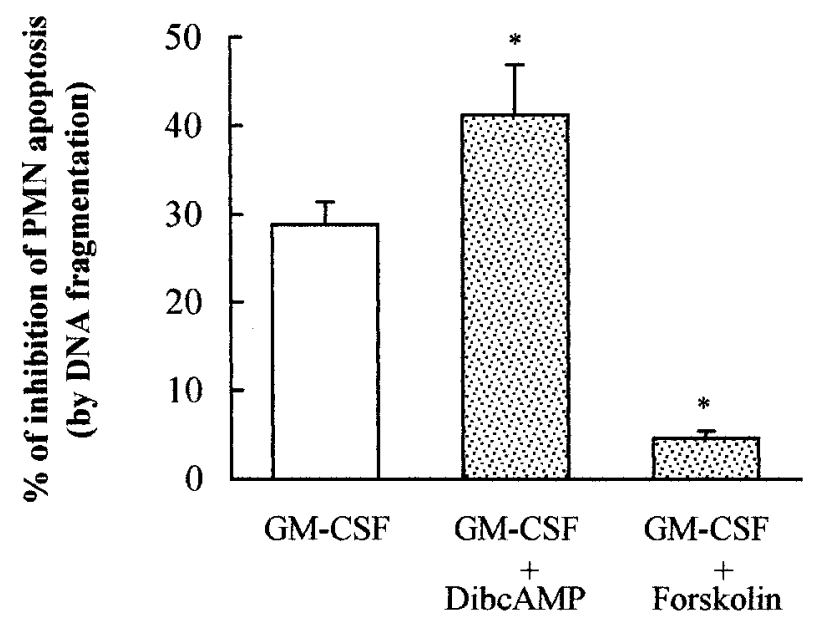

FIG. 3. Modulating effects of cAMP-elevating agents on GMCSF-mediated inhibition of Fas-induced neutrophil apoptotic death. PMN were pretreated for $2 \mathrm{~h}$ with GM-CSF (1000 UI/ $\mathrm{ml}$ ), either used alone (white column) or in combination with dibutyryl cAMP $\left(2 \times 10^{-3} \mathrm{M}\right)$ or forskolin $\left(10^{-4} \mathrm{M}\right)$ (dotted columns), before the addition of $\mathrm{mAb} \mathrm{CH}-11(150 \mathrm{ng} / \mathrm{ml})$. After a $12 \mathrm{~h}$ culture, cells were recovered and further processed for DNA fragmentation analysis. Results are expressed as percentage of inhibition (mean \pm SD) of low to high molecular weight DNA ratio induced by the various substances in 12 independent donors. Significance versus homologous cells suspensions treated with GM-CSF only: ${ }^{*} p<0.001$. common transductional step is likely to occur at a later phase during the signaling events triggered by the two molecules.

Previous reports on the role of GM-CSF in the adenylate cyclase and the cAMP transduction pathw ay have led to contrasting results, strictly related to cell lineage. ${ }^{21-24}$ Of note however, our data are in accordance with studies on human leukemia cells, showing a significant reduction of cAMP intracellular levels following cytokine cell challenge. ${ }^{23}$ Wei et al. ${ }^{25}$ have recently found that GM-CSF-mediated suppression of neutrophil apoptosis is dependent on the activation of Lyn kinase, a member of the Src tyrosine kinase family. Whether this early signal pathway may account for the inhibition of adenylate cyclase induced by GM-CSF will certainly be a subject of further investigation.

Although the nature of the saturable enzymatic activity common to GM-CSF- and cAMP-mediated pathways has not been directly investigated in this study, it is tempting to hypothesize that such a role might be carried out by a transcription factor, called CREB (cAMP-response element-binding protein), whose activation might, in turn, be responsible for the expression of genes involved in the regulation of apoptotic phenomenon. Besides PKA-induced CREB activation, which represents the way through which cAMP signals reach the nucleus, ${ }^{26}$ it has, in fact, been recently demonstrated that phosphorylation of CREB is required for transcriptional activation in response to $\mathrm{GM}-\mathrm{CSF}^{27}$ such an effect occurring via a PKAindependent pathway. ${ }^{24}$ Moreover, by using a thymoma cell line system, Dowd et al. ${ }^{28}$ have reported that this protein is actively involved in the apoptotic events induced by cAMP, glucocorticoids or calcium increase. More generally, CREB phosphorylation might thus represent a transductional step common 
to a variety of molecules influencing apoptosis, its activation determining either apoptotic or rescuing effects according to the cell type involved.

Other than being inhibited in its activity by GM-CSF, forskolin may in turn reduce the cytokine capacity to suppress neutrophil apoptosis. The only reasonable explanation for such an effect is that the molecule may interfere $w$ ith the signaling pathway triggered by GM-CSF, either inhibiting some enzymatic activity or activating some inhibitory molecule. Regardless of either possibility, this finding would imply a novel forskolin function, which adds to that already known of adenylate cyclase activator.

We have previously reported ${ }^{10}$ with other groups ${ }^{11}$ that Fas-triggered neutrophil apoptosis may be partially suppressed by some proinflammatory mediators, including GM-CSF as well as granulocyte-CSF and lipopolysaccharide. In the current study, we further extend these findings, showing that although dibutyryl cAMP or forskolin does not influence the apoptotic events induced by Fas antigen activation, they can still modulate the antiapoptotic activity mediated by GM-CSF, with effects similar to those respectively exerted on spontaneous neutrophil cell death. Accordingly, it is conceivable to suppose that cAMP-elevating agents, being per se unable to affect the Fas-induced apoptotic outcome, may still interfere with the Fas signaling at a subliminar level, making it more or less responsive to GM-CSF activity. An alternative possibility may however arise from a more detailed analysis of results. Whether a $12 \mathrm{~h}$ incubation time is sufficient to induce a Fas-mediated apoptotic death in the majority of cells, such a time still allows for the occurrence of spontaneous apoptotic events in about $25 \%$ of neutrophils, as evaluated from control cultures in the absence of anti-Fas mAb (see Fig. 2). Under these experimental conditions, it is thus possible that the rescuing effect of GM-CSF is related to the antiapoptotic activity exerted towards the neutrophil population undergoing a spontaneous apoptotic death, rather than to its capacity to interfere with the Fas signaling, as previously supposed. $^{10,11}$ Accordingly, the different modulation exerted by GM-CSF and cAMP on neutrophil cell death in 'Fas-treated' cultures might rely on the different time course activity of the two molecules on spontaneous apoptotic events. To support this view, in parallel experiments, we find that the inhibitory effect of GM-CSF on spontaneous neutrophil apoptosis occurs very early in culture, peaks at $12 \mathrm{~h}$ and then gradually decreases, whereas cAMP-mediated antiapoptotic activity starts later, but is still evident after a $48 \mathrm{~h}$ incubation time (data not shown).

Taken together, the data are consistent with the conclusion that even though both cAMP and GM-CSF are able to inhibit neutrophil cell death, a negative modulation of cAMP signaling occurs as a consequence of cytokine cell challenge. Since adenylate cyclase activation is a nonspecific event and cAMP acts as second messenger for a variety of molecules, ${ }^{29}$ the in vivo administration of GM-CSF may have an important counterpart, by preventing an abnormal neutrophil survival, and then favouring the increase of newborn PMN at blood level. ${ }^{30}$

\section{References}

1. Lehrer RI, Ganz T, Selsted ME, Babior BM, Curnutte JT. Neutrophils and host defense. Ann Intern Med 1988; 109: 127-142.

2. Weiss SJ. Tissue destruction by neutrophils. N Engl J Med 1989; 320 365-376.

3. Lloyd AR, Oppenheim JJ. Poly's lament: the neglected role of the polymorphonuclear neutrophil in the afferent limb of the immune response. Im munol To day 1992; 13: 169-172.

4. Colotta F, Re F, Polentarutti N, Sozzani S, Mantovani A. Modulation of granulocyte survival and programmed cell death by cytokines and bacterial products. Blood 1992; 80: 2012-2020.

5. Haslett C. Resolution of acute inflammation and the role of apoptosis in the tissue fate of granulocytes. Clin Sci 1992; 83: 639-648.

6. Cox G. Glucocorticoid treatment inhibits apoptosis in human neu trophils. Separation of survival and activation outcomes. I Immunol 1995; 154: 4719-4725.

7. Homburg CHE, de Haas M, von dem Borne AEGKr, Verhoeven AJ, Reutelingsperger CPM, Roos D. Human neutrophils lose their surface Fc $\gamma$ RIII and acquire annexin V binding sites during apoptosis in vitro. Blood 1995; 85: 532-540.

8. Cohen JJ. Overview: mechanisms of apoptosis. I. Apoptosis. Im munol today 1993; 14: 126-130.

9. Savill J, Dransfield I, Hogg N, Haslett C. Vitronectin receptor-mediated phagocytosis of cells undergoing apoptosis. Nature 1990; 343: $170-173$.

10. Liles WC, Kiener PA, Ledbetter JA, Aruffo A, Klebanoff SJ. Differential expression of Fas (CD95) and Fas ligand on normal human phagocytes: implications for the regulation of apoptosis in neutrophils. J Exp Med 1996; 184: 429-440.

11. Tortorella C, Piazzolla G, Spaccavento F, Pece S, Jirillo E, Antonaci S. Spontaneous and Fas-induced apoptotic cell death in aged ne utrophils. J Clin Im munol 1998; 18: 321-329.

12. Brach MA, de Vos S, Gruss HJ, Herrmann F Prolongation of survival of human polymorphonuclear neutrophils by granulocyte-macrophage colony-stimulating factor is caused by inhibition of programmed cell death. Blood 1992; 80: 2920-2924

13. Lee $A$, Whyte $M K B$, Hasle tt C. Inhibition of apop tosis and prolongation of neutrophil functional longevity by inflammatory mediators. J Leukocyte Biol 1993; 54: 283-288.

14. Pericle F, Liu JH, Diaz JI, et al. Interleukin-2 prevention of apoptosis in human neutrophils. Eur I Im munol 1994; 24: 440-444.

15. Anderson KL, Anderson G, Michell RH, Jenkinson EJ, Owen JJ. Intracellular signaling pathways involved in the induction of apoptosis in immature thymic T lymphocytes. J Im munol 1996; 156: 4083-4091.

16. Lomo J, Blomhoff HK, Beiske K, Stokke T, Smeland EB. TGF-beta 1 and cyclic AMP promote apoptosis in resting human B lymphocytes. J Im munol 1995; 154: 1634-1643.

17. Rossi AG, Cousin JM, Dransfield I, Lawson MF, Chilvers FR, Haslett C. Agents that elevate cAMP inhibit human neutrophil apoptosis. Biochem Biophys Res Comm 1995; 217: 892-899.

18. Ottonello L, Gonella R, Dapino P, Sacchetti C, Dallegri F. Prostaglandin E2 inhibits apoptosis in human neutrophilic polymorphonuclear leukocytes: role of intracellular cyclic AMP levels. Exp Hematol 1998; 26: $895-902$.

19. Böyum A. Isolation of mononuclear cells and granulocytes from human blood. Scand J Clin Lab Invest 1968; 21 (Suppl): 77-89.

20. Duke RC, Cohen JJ. Morphological and biochemical assays of apoptosis. In: Coligan JE, Kruisbeek AM, Margulies DH, Shevac EM, Strober W, eds Current Protocols in Im munology. New York: John Wiley \& Sons, 1992: pp. 3.17.1-3.17.16

21. Piquet-Pellorce C, Dy M. Prostaglandin E2 potentiates granulocytemacrophage colony-stimulating factor-induced histamine synthesis in bone marrow cells: role of cAMP. Life Sci 1991; 48: 2377-2382.

22. Young MRI, Lozano Y, Djordjevic A, et al. Granulocyte-macrophage colony-stimulating factor stimulates the metastatic properties of Lew is lung carcinoma cells through a protein kinase A signal-transduction pathway. Int J Cancer 1993; 53: 667-671.

23. Schwartz EL, Chamberlin H, Brechbuhl AB. Regulation of c-myc expression by granulocyte-macrophage colony-stimulating factor in human leukemia cells. Blood 1991; 77: 2716-2723

24. Wong A, Sakamoto KM. Granulocye-macrophage colony-stimulating factor induces the transcriptional activation of $e g r-1$ through a prote in kinase A-independent pathway. J Biol Chem 1995; 270: 30271-30273. 
25. Wei S, Hong Liu J, Epling-Burnett PK, et al. Critical role of Lyn kinase in inhibition of neutrophil apoptosis by granulocyte-macrophage colonystimulating factor. J Im munol 1996; 157: 5155-5162.

26. Gonzales GA, Montminy MR. Cyclic AMP stimulates somatostatin gene transcription by phosphorylation of CREB at serine 133. Cell 1989; 59. 675-680.

27. Lee JHJ, Mignacca RC, Sakamoto KM. Transcriptional activation of egr-1 by granulocyte-macrophage colony-stimulating factor but not interleukin 3 requires phosphorylation of cAMP response element-binding protein (CREB) on serine 133. J Biol Chem 1995; 270: 15979-15983.

28. Dowd DR, Ryerse JS, MacDonald PN, Miesfeld RL, Kamradt MC. Crosstalk during $\mathrm{Ca}^{2+}$, cAMP-, and glucocorticoid-induced gene expression in lymphocytes. Mol Cell Endocrinol 1997; 128: 29-37.
29. Beato M. Gene regulation by steroid hormones. Cell 1989; 56: $335-344$

30. Sakamoto KM, Gasson JC. Clinical applications of granulocyte-macrophage colony-stimulating factor. Int J Cell Cloning 1991; 9: 531-541.

ACKNOWLEDGEMENTS. This w ork w as supported by grants ( $40 \%$ and $60 \%)$ from Ministero dell'Università e della Ricerca Scientifica e Tecnologica (MURST), Rome, Italy.

\section{Received 5 October 1998; \\ accepted 13 October 1998}




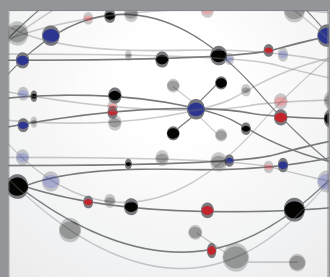

The Scientific World Journal
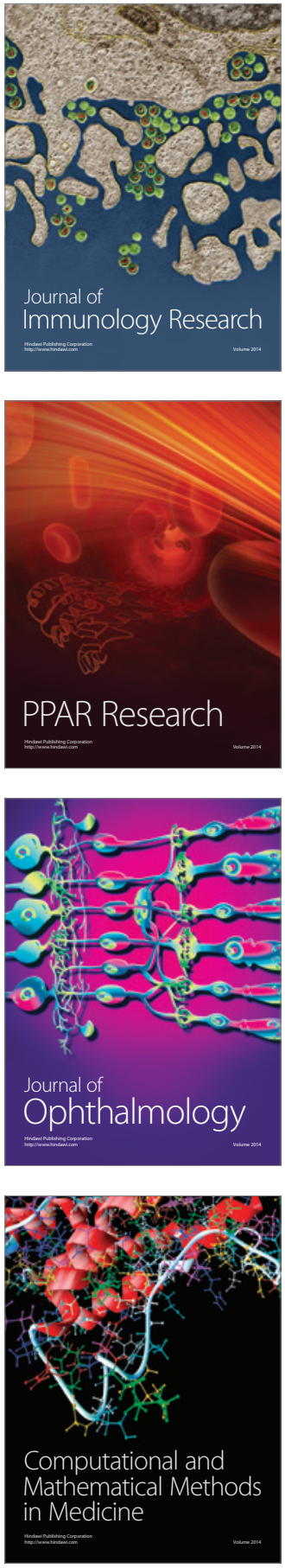

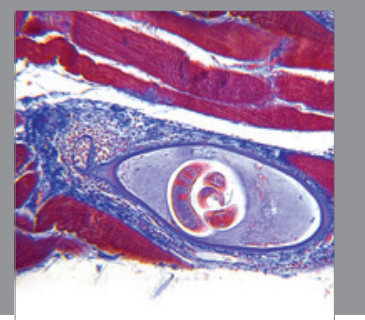

Gastroenterology

Research and Practice
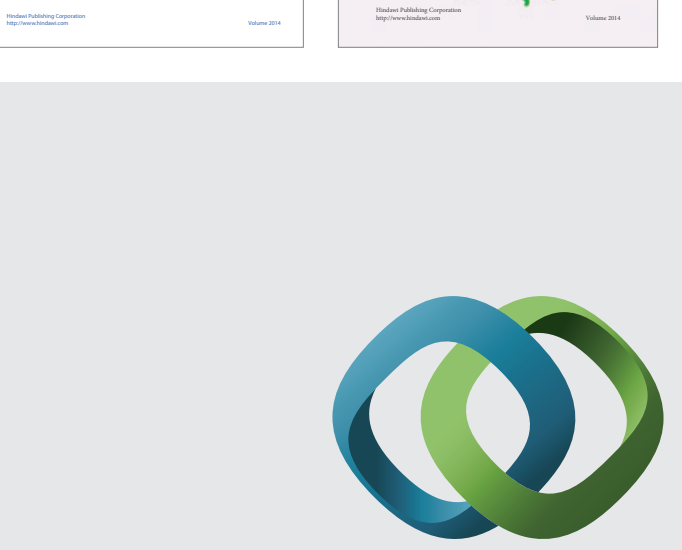

\section{Hindawi}

Submit your manuscripts at

http://www.hindawi.com
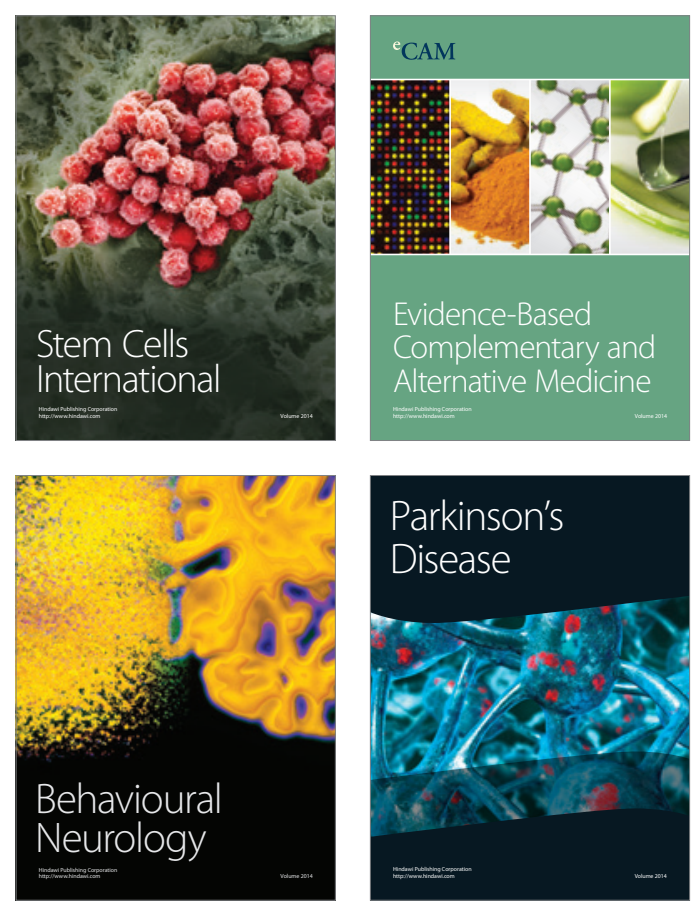

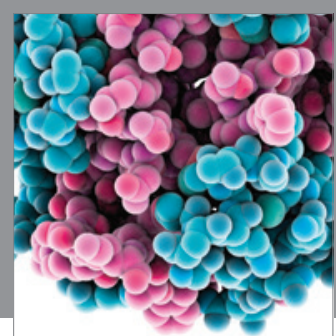

Journal of
Diabetes Research

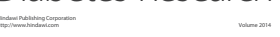

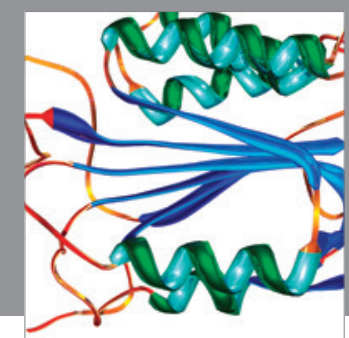

Disease Markers
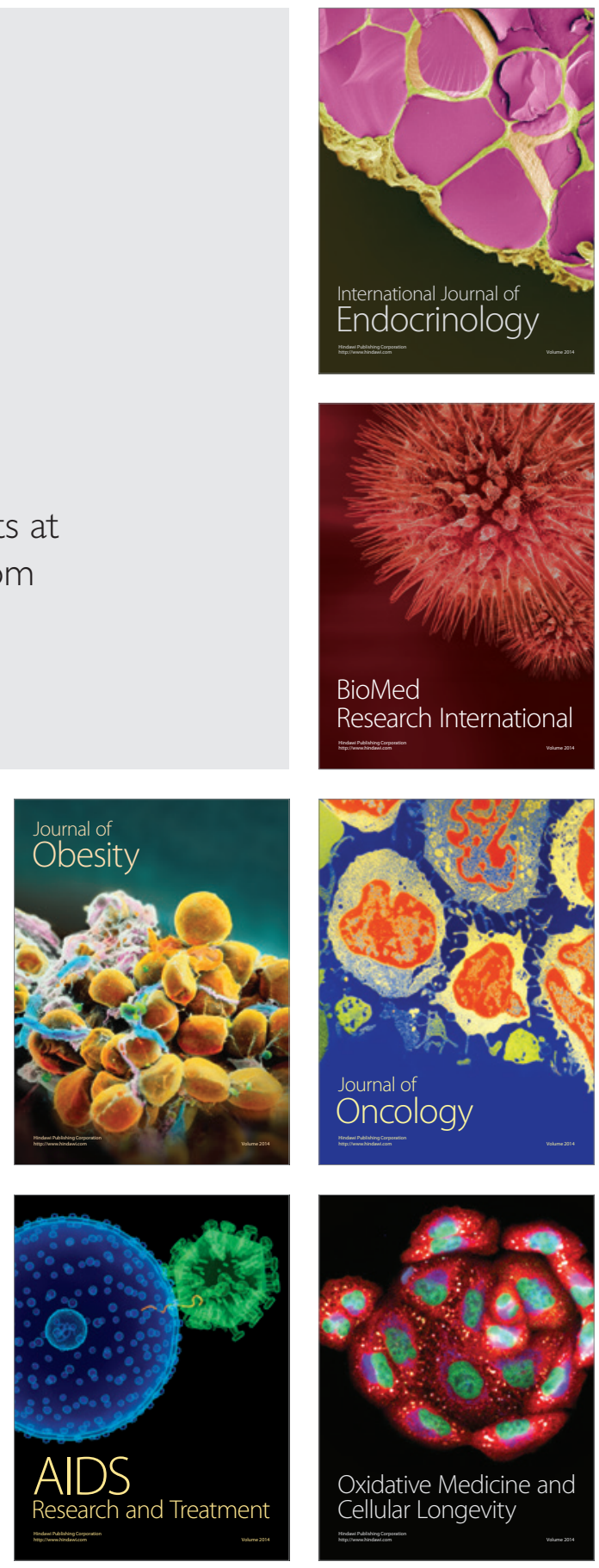